\title{
Commentary on Nguyen et al. “Living with Male Breast Cancer: A Qualitative Study of Men's Experiences and Care Needs"
}

\author{
Nicole Ernstmann ${ }^{a, b} \quad$ Christoph Kowalski ${ }^{c}$ \\ ${ }^{a}$ Department for Psychosomatic Medicine and Psychotherapy, Center for Health Communication and Health \\ Services Research (CHSR), University Hospital Bonn, Bonn, Germany; ${ }^{\mathrm{b}}$ Center for Integrated Oncology (CIO) Bonn, \\ Bonn, Germany; ${ }^{\complement}$ German Cancer Society, Berlin, Germany
}

Dear Editor,

In their recent article, Nguyen et al. [1] presented research on experiences and needs of male breast cancer patients in Germany. Breast cancer in men is a rare condition, and studies exploring the needs of male breast cancer patients are still needed. The authors conducted semi-structured interviews with $n=18$ patients and performed qualitative content analysis. We congratulate the authors to contributing to a better understanding of the specific needs of these men and their caregivers.

Describing the current state of research, the authors refer to the health services' research gap concerning male breast cancer. Some of these gaps have been addressed in prior work conducted by a multidisciplinary research team, including the authors of this letter, within the N-MALE study ("Male breast cancer: patients' needs in prevention, diagnosis, treatment, rehabilitation, and follow-up care") that was funded by the German Cancer Aid between 2016 and 2018. Results of this study have been published in this Breast Care [2] as well as others [3-5]. These results are based on a study sample of $n=100$ male breast cancer patients across Germany. We used a mixed-methods approach by triangulating qualitative interview data from $n=27$ patients and standardized survey data from 100 patients. In addition, we incorporated the perspective of health professionals involved in male breast cancer care and conducted semi-structured interviews with $n=23$ participants and two focus group discussions with $n=16$ participants.

The central findings of both Nguyen et al. [1] as well as the NMALE study regarding the patient perspective are in accordance: both studies report some experiences of stigmatization and of shortcomings including barriers in access to gynecological outpatient care and unclear responsibilities. This replication of findings validates the results of both studies. Besides the qualitative exploration of the patients' perspectives, our survey results can help quantify the occurrence of stigmatization or barriers to receiving care. Nguyen et al. [1] describe "a lack of awareness and experience of treating males among health professionals" as a central experience male breast cancer patients make. Our data analyzing the healthcare provider interviews show a similar pattern: we found insecurities in terms of treatment recommendations or responsibilities, and a lack of interdisciplinary cooperation, especially in follow-up care [5].

Following the N-MALE study's initial results, two of the findings that were also addressed by Nguyen et al. [1] were investigated in more detail or processed; one considers the challenges of reimbursement of male breast cancer care in gynecology practices [6]. Based on a representative national survey of the associations of statutory health insurance physicians in all federal states of Germany, we found divergent practices in the states [7]. In short, office-based gynecologists get their services reimbursed depending on the state and the respective association of statutory health insurance physicians. This should be considered when discussing individual doctors' responsibilities and instruction for reimbursement for male breast cancer treatment [1]. Second, addressing the lack of adequate information material, we summarized our results from the patients' and the providers' perspective in fact sheets, together with a conversation prompt sheet for patients to get prepared for their medical encounters (in German language) [7].

Bringing together the results of Nguyen et al. [1] and our research [2], the central implications for male breast cancer care are becoming more evident: awareness of the disease should be increased, study evidence for male breast cancer should be generated, information material should be tailored to men, access to outpatient gynecological care should be ensured, and information on this responsibility should be part of trainings for health professionals.

\section{Disclosure Statement}

Christoph Kowalski is an employee of the German Cancer Society. 


\section{Funding Sources}

No additional funding was received for the writing of this letter. Our N-MALE study referred to in this letter ([3], [4], [5], [6]) was supported by the German Cancer Aid under the grant No. 111742.

\section{Author Contributions}

Both authors contributed equally to this letter.

\section{References}

1 Nguyen TS, Bauer M, Maass N, Kuduszkiewicz H. Living with Male Breast Cancer: A Qualitative Study of Men's Experiences and Care Needs. Breast Care (Basel). DOI: $10.1159 / 000501542$.

2 Halbach S, Midding E, Ernstmann N, Wuerstlein R, Weber R, Christmann S, et al. Male breast cancer patients' perspectives on their health care situation - A mixed methods study. Breast Care (Basel). DOI: $10.1159 / 000501956$.

3 Midding E, Halbach SM, Kowalski C, Weber R, Wuerstlein R, Ernstmann N. Men With a 'Woman's Disease': Stigmatization of Male
Breast Cancer Patients - A Mixed Methods Analysis. Am J Mens Health [Internet]. Available from: https://journals.sagepub.com/doi/ $10.1177 / 1557988318799025$.

4 Midding E, Halbach SM, Kowalski C, Weber R, Wuerstlein R, Ernstmann N. Social support of male breast cancer patients - a mixedmethods analysis. Am J Mens Health [Internet]. Available from: https://journals.sagepub. com/doi/full/10.1177/1557988319870001.

5 Ernstmann N, Midding E, Halbach S, Wuerstlein R, Weber R, Christmann S, et al. Breast Cancer in Men: Health Care Professionals' Perspectives on the Multidisciplinary Care of a Rare Disease [article in German]. Gesundheitswesen. DOI: 10.1055/a-1005-6978.

6 Halbach S, Midding E, Wesselmann S, Wuerstlein R, Ernstmann N. Inanspruchnahme gynaekologischer Facharztleistungen durch Maenner mit Brustkrebs(-verdacht). Forum DKG. 2018;33(1):7-8.

7 Center for Health Communication and Health Services Research (CHSR) [Internet]. Bonn: N-MALE results: Fact-Sheets and Prompt Sheets for patients and caregivers [cited 2019 Sep 4]. Available from: https:// www.ukbonn.de/42256BC8002AF3E7/ direct/chsr-aktuelles. 